\title{
Recent U.S. advances in ion-beam-driven high energy density physics and heavy ion fusion*
}

\author{
B. G. Logan, F.M. Bieniosek, C.M. Celata, J. Coleman, W. Greenway, E. Henestroza, J.W. \\ Kwan, E. P. Lee, M. Leitner, P.K. Roy, P.A. Seidl, J-L. Vay, W.L. Waldron, S.S. Yu \\ Lawrence Berkeley National Laboratory, Berkeley, CA 94720, USA \\ J.J. Barnard, R.H. Cohen, A. Friedman, D.P. Grote, M. Kireeff Covo, A.W. Molvik, S.M. Lund, \\ W.R. Meier, W. Sharp \\ Lawrence Livermore National Laboratory, Livermore, CA, USA \\ R.C. Davidson, P.C. Efthimion, E.P. Gilson, L. Grisham, I.D. Kaganovich, H. Qin, A.B. Sefkow, \\ E.A. Startsev Princeton Plasma Physics Laboratory, Princeton, NJ 08543, USA \\ D. Welch, Voss Scientific, Albuquerque, NM, USA \\ C. Olson, Sandia National Laboratories, USA
}

\begin{abstract}
During the past two years, significant experimental and theoretical progress has been made in the U.S. heavy ion fusion science program in longitudinal beam compression, ion-beam-driven warm dense matter, beam acceleration, high brightness beam transport, and advanced theory and numerical simulations. Innovations in longitudinal compression of intense ion beams by $>50 \mathrm{X}$ propagating through background plasma enable initial beam target experiments in warm dense matter to begin within the next two years. We are assessing how these new techniques might apply to heavy ion fusion drivers for inertial fusion energy.
\end{abstract}

\section{Introduction}

A coordinated heavy ion fusion science program by the Lawrence Berkeley National Laboratory, Lawrence Livermore National Laboratory, and Princeton Plasma Physics Laboratory (the HeavyIon Fusion Science Virtual National Laboratory), together with collaborators at Voss Scientific and Sandia National Laboratories, pursues research on compressing heavy ion beams towards the high intensities required for creating high energy density matter and fusion energy. In previous research, experiments [1] and simulations [2] showed $>100 \mathrm{X}$ increases in focused beam intensities in the Neutralized Transport Experiment by transverse compression of an intense ion beam propagating through a background plasma to neutralize $>90 \%$ of the beam space charge. Section 2 describes recent work on longitudinal compression of an intense beam within neutralizing plasma, and in Sec. 3 we describe studies of initial warm dense matter target experiments that can begin in 2008 after transverse and longitudinal beam compression are combined. Progress in testing a novel Pulse Line Ion Accelerator (PLIA) is described in Sec. 4, e-cloud experiments, theory and simulations in Sec 5, advanced injectors in Sec 6, and advanced theory and simulation models in Sec 7. Section 8 discusses potential applications to heavy ion fusion drivers, and conclusions are given in Sec. 9.

\section{Neutralized drift compression}

Our approach to maximize both beam energy deposition and heating uniformity is to place the peak in ion beam $\mathrm{dE} / \mathrm{dx}$ at the center of thin targets (a few microns' thickness, corresponding to the range of $\mathrm{MeV}$ ion beams) [3]. Such thin targets will hydro-expand in a few nanoseconds at 1 $\mathrm{eV}$ temperature, so short pulses of a few ns are needed instead of the few $\mu$ s pulses previously used. Longitudinal compression of an ion bunch using a velocity ramp head-to-tail while traveling through neutralizing background plasma provides a means of generating ion beam 
pulses short enough to be consistent with the hydro expansion time of few-micron-thick target foils for near-term warm dense matter physics experiments. In the Neutralized Drift

Compression Experiment [4] (NDCX-Fig. 1), an induction core adds a velocity ramp from the head to the tail of a selected 200 to $400 \mathrm{~ns}$ portion of a $25 \mathrm{~mA}, 300 \mathrm{kV} \mathrm{K}$ ion beam. The ramp is applied with a specially shaped induction drive pulse of $100 \mathrm{kV}$ amplitude. The rear of the selected beam slice catches up with the head particles in a 1.3-meter drift section that is pre-filled with plasma confined in a weak solenoid magnetic field. The drift compression section provides space-charge neutralization during axial compression. Using a compressing induction voltage waveform closely matched to ideal waveforms from simulations $[5,6]$, we have achieved $60 \mathrm{X}$ current amplification [7] (Fig.2). A longitudinal beam temperature $\mathrm{T}_{\mathrm{z}}<1.5 \mathrm{eV}$ is measured with an improved-resolution electrostatic energy analyzer, which is consistent with the low longitudinal beam temperatures that simulations require in order to explain the large compression factors that are achieved. A longer plasma source [8] will be tested soon to optimize neutralization of beams [9] over a greater range of distances and velocity ramps.

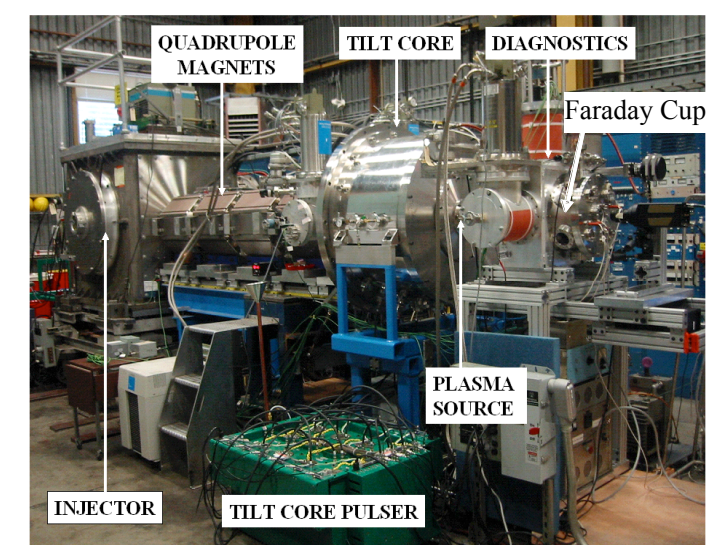

Figure 1. The new NDCX-1A facility began operation in December 2004. The facility utilizes the injector from the previous NTX experiment, together with an induction "tilt" core (center), to induce a velocity ramp to compress the beam. There is also a longer plasma-filled drift tube between the tilt core and the end diagnostics, compared to NTX.

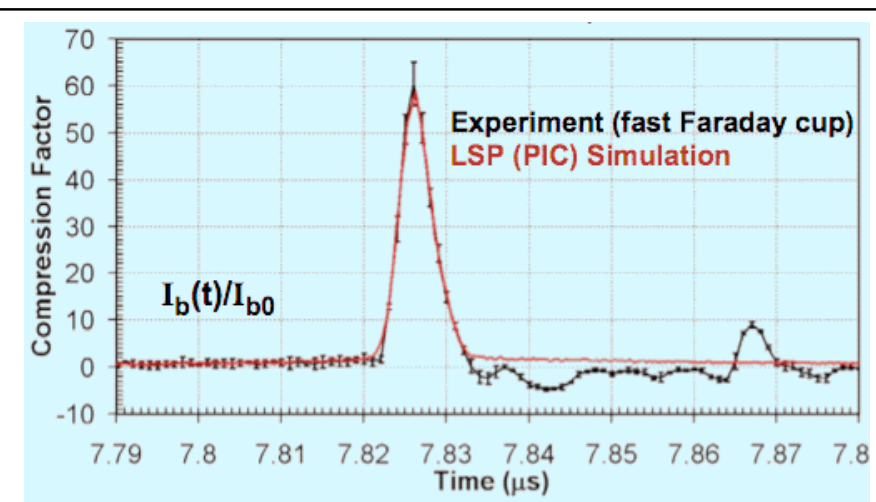

Figure 2. Comparison of fast Faraday cup current waveform with LSP PIC simulations for an NDCX compression experiment. When the actual, experimentally realized waveforms were inserted in the simulations (red curve), good agreement with the data is seen. (See papers by Peter Seidl, et.al., Adam Sefkow, and Dale Welch, these proceedings.)

\section{Design of experimental ion-beam-driven warm dense matter target experiments}

Over the last year we have evaluated an initial set of ion-beam-heated experiments $[10,11]$ to contribute to the science of warm dense matter as expeditiously as possible using modest improvements [12] to present beam facilities (NDCX and HCX) The list of experiments below is planned to yield scientifically interesting results at progressively higher beam intensities and increasing target temperatures.

a. Beam-induced transient emission and absorption experiments in transparent insulators (on HCX and NDCX). The beam excites electrons to higher energy states, resulting in a darkening of the otherwise transparent material. The goal is to corroborate the understanding of the phenomena that have been observed at higher temperatures.

b. Experiment to measure target temperature and conductivity using a beam compressed both transversely and longitudinally (on NDCX). Here the best focus (both longitudinally and 
transversely) that can be obtained on the present NDCX experiment will be used to raise the target temperature as high as possible, and begin to make hydrodynamic and conductivity experiments.

c. Positive - negative halogen ion plasma experiment (kT $>\sim 0.4 \mathrm{eV}$ ) [13] (on NDCX with focusing solenoid, or pulse compressed HCX with focusing solenoid). The conductivity of such a novel plasma composed primarily of positive and negative ions may be similar to that of semiconductors at high densities.

d. Two-phase liquid-vapor metal experiments ( $\mathrm{kT}>0.5-1 \mathrm{eV}$ ) (on NDCX with focusing solenoid or pulse compressed HCX with focusing solenoid or NDCX-upgraded). The exact phase transition boundary for a number of metals is unknown and the dynamics passing through this phase is also important to determine.

e. Critical point measurements ( $\mathrm{kT}>1 \mathrm{eV}$ ) (possibly only on NDCX-upgraded). The critical point occurs at the highest temperature for which a distinction between the gaseous and liquid state can be observed.

In addition, it is planned to carry out metallic foam heating experiments at GSI that will begin to explore the physics of foam targets as well as possible measurements of $\mathrm{dE} / \mathrm{dX}$ in metallic foam. Ion stopping may be different when the time between collisions is less than the relaxation timescale of the ion in the excited state.

\section{Pulse Line Ion Accelerator (PLIA)}

The first acceleration of non-relativistic $\mathrm{K}+$ ion bunches with a helical slow wave structure immersed in a coaxial dielectric (Pulse Line Ion Accelerator [14], Fig. 3) has been demonstrated Due to the traveling wave that provides the accelerating field, significant energy amplification has been achieved with modest voltage pulses. Depending on the phase of ions with respect to the traveling wave, a beam energy modulation of $-80 \mathrm{keV}$ to $+150 \mathrm{keV}$ on the NDCX beam was measured using a PLIA input voltage waveform of $-21 \mathrm{kV}$ to $+12 \mathrm{kV}$. The resulting beam energy modulation is consistent with WARP simulations (Fig. 4). We are currently studying the causes and possible remedies of a vacuum breakdown that presently limits $<\mathrm{E}_{\mathrm{z}}><150 \mathrm{kV} / \mathrm{m}$ [15]. If we can achieve high gradients through continuing modeling and experiments, the PLIA may greatly reduce the cost per volt for accelerators used to heat target experiments using ions near the peak of $\mathrm{dE} / \mathrm{dx}$.

\section{High brightness beam transport}

We have refined electron-cloud and gas experiments in the High Current Experiment (HCX) with improved diagnostics [16] and models [17]. We made the first absolute measurement of ecloud densities [18], and increased the understanding of electron emission [19]. We find significant agreement between measured and simulated e-cloud effects on a high current ion beam transported through four quadrupole magnets in HCX. As in the beam compression experiments in NDCX discussed above, advanced simulations also closely support the e-cloud experiments in HCX. Figure 5 below shows a snapshot of electron density in a simulation of the HCX beam being substantially neutralized in the last magnet from secondary electrons drifting in from the end wall on the right [20]. These simulations are made possible by a large time-step particle mover that allows us to simulate complex electron drifts in 3-D magnetic fields. Figure 5 exhibits large amplitude ( $\sim$ beam space charge density level) oscillations in the electron cloud at $6 \mathrm{MHz}$, consistent in frequency and amplitude with those measured. We are beginning to test these e-cloud models in solenoid transport experiments in NDCX (Fig. 6), so that we can 


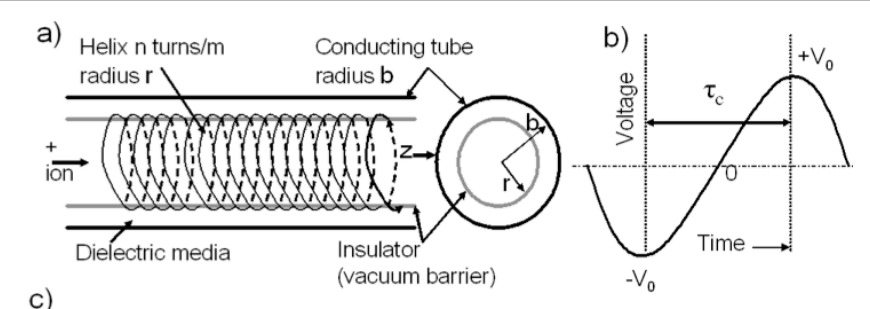

c)

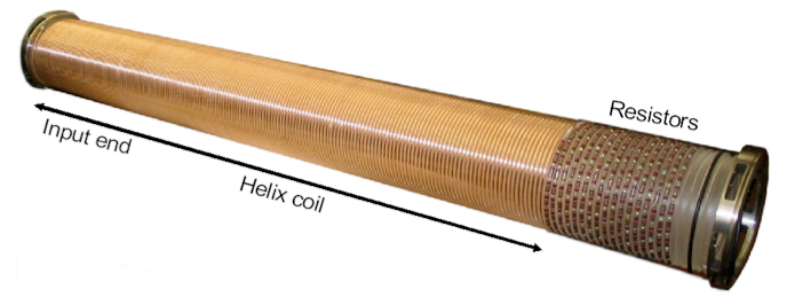

Figure 3. A schematic of the helical pulse line structure. (a) The helical pulse line of radius $r$ is located inside a conducting cylinder of radius $b$, and a dielectric medium is located in the region outside the helix; (b) schematic of a drive voltage waveform applied at the helix input; and (c) a one-meter-long helix constructed for the PLIA experiments.
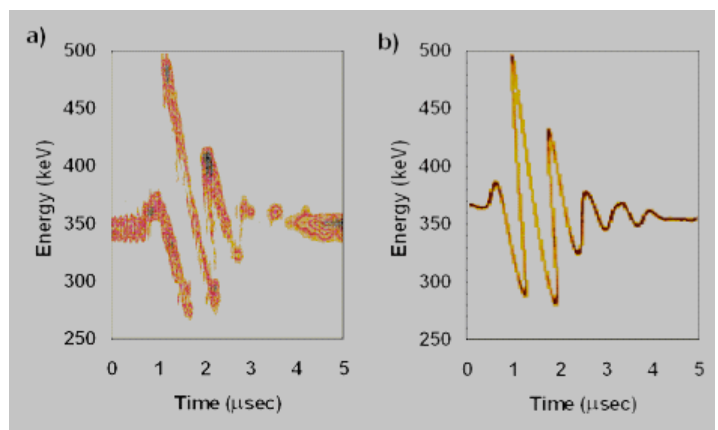

Figure 4. The energy distribution (measured with a new energy analyzer) of NDCX $\mathrm{K}^{+}$beam ions accelerated through a $1 \mathrm{~m}$ PLIA section (Fig. 1). The measured ion output energies (a) are modulated depending on the ion phase with respect to the ringing waveform. WARP-3D simulations (b) reproduce the measured energy modulation. (See papers by P.K. Roy, E. Henestroza, and J. Coleman, these proceedings).

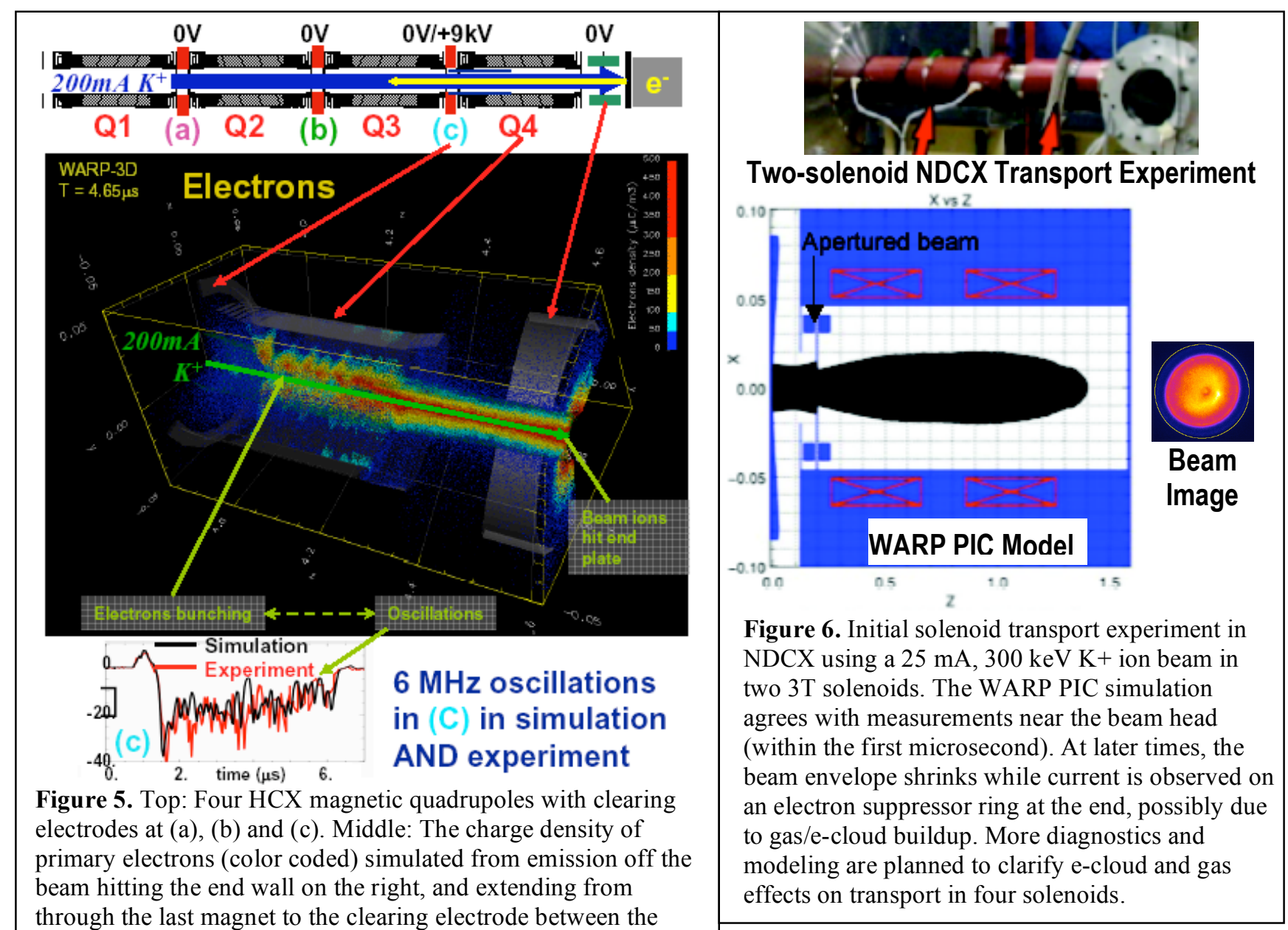


compare e-cloud effects in solenoids as well as in quadrupoles. A predictive e-cloud capability is important to design future heavy-ion-beam facilities such as NDCX-II, the Integrated BeamHigh Energy Density Physics Experiment (IB-HEDPX), a future user facility for heavy-iondriven warm dense matter experiments, and heavy ion drivers.

\section{Advanced theory and simulation tools}

Advanced theory and simulations have improved our understanding of the collective stability properties of intense heavy ion beams and beam-plasma interactions, and of multi-species interactions with gas and strong electron "clouds" affecting intense beam transport [21 - 24]. Strongly anisotropic beams may be subject to electrostatic Harris-type instability [25] which may increase the parallel beam temperature and thus may inhibit subsequent longitudinal neutralized drift compression. Collective processes of an intense ion beam with charge-neutralizing background plasma, such as the electrostatic two-stream instability, the electromagnetic multispecies Weibel instability, and the resistive hose instability [24, 26] may also affect ultimate focusing of compressed neutralized beams. Conditions minimizing deleterious effects of collective processes on beam quality have been identified [27].

Our simulation tools for treating interaction of intense ion beams in accelerators with gas and electron cloud effects have seen considerable development over the past several years. This progress has enabled studies of the new regimes required for high energy density physics and warm dense matter studies. The tools and numerical techniques are also proving very useful for a broad range of accelerator physics and particle trap applications. A comprehensive set of models [28] governing the interaction of positively-charged beams with electron clouds (eclouds) and gas has been developed and implemented in the WARP code. Secondary electron emission from walls, charge exchange, neutral emission, and other processes are now included. The package encapsulates several important plasma-wall interaction physics effects. Figure 7 shows how the various plasma wall interactions relate to one another.

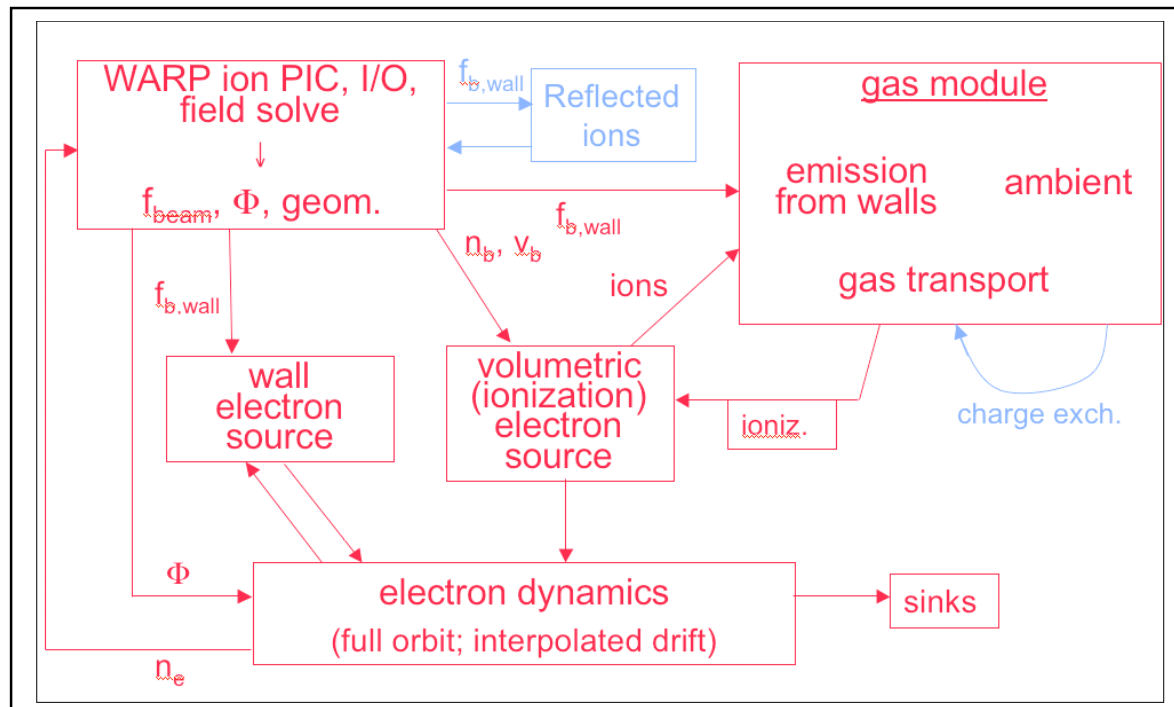

Figure 7. We have almost completed the implementations of all of the modules in the roadmap for developing self-consistent modeling of electron and gas cloud effects in high intensity ion accelerators. (Implemented modules are in red; those undergoing implementation are in blue.) See papers by Ron Cohen and Jean Luc Vay, these proceedings. 


\section{Development of advanced injectors}

The Converging - Beamlets Experiment on the 500-kV test stand at LLNL (STS-500) was successfully completed in 2005 [29]. In operation up to $400 \mathrm{keV}$ beam energy at the designed beam current of near $80 \mathrm{~mA}$, the beam pulses were reproducible without voltage breakdown issues. Simulations using WARP3d were used to design the experiments, and results are in good agreement with simulations [30]. This concluded several years of effort in the development of an advanced, compact, low cost high-current injector for heavy ion fusion drivers. This experiment has validated the multi-beamlet injector concept, producing high-brightness, high-current beams using a very compact injector. It establishes a new injector option for heavy ion accelerators, such as modular solenoid and multiple-beam induction linacs. This approach also allows potential use of high power ECR plasma sources [31] of higher charge state ions such as $\mathrm{Ar}^{+8}$, which is especially important in the context of modular HIF drivers that require high currents of high charge-to-mass-ratio ions, in order to lower the cost and boost the efficiency of single-beam solenoid-focused linacs.

\section{Studies of neutralized drift compression applied to heavy ion fusion drivers}

Studies of the application of neutralized beam compression and focusing (NDC) to heavy ion fusion linac drivers have continued since 2004. The primary benefit of removing space charge during drift compression and focusing is expected to be allowed use of higher charge-to-mass ratio ions to reduce linac voltage, length and cost, when the beam perveance would be otherwise too high to drift compress and focus in vacuum. In 2004, systems analysis [32] found that use of $200 \mathrm{MeV} \mathrm{Ne}^{+1}$ with NDC could potentially reduce $6.4 \mathrm{MJ}$ driver costs by about a factor of about two, for both a multiple-beam quadrupole-focused single induction linac driver (MQ driver) as well as for a driver system of 24 modular, single-beam solenoid-focused induction linacs (MS driver), under the assumption that suitable injectors and final focus/chamber designs can be developed. Recent improvements in high-voltage induction cells [33] have allowed DARHT-II to become one of the largest induction linacs operating in the world, now undergoing scaled beam acceleration tests. Later this year, DARHT-II will test fast downstream kicker magnets for multipulsing $\mathrm{kA}$ electron beams, and this technology is relevant to time-dependent chromatic error corrections. There are several issues remaining to be assessed, including high brightness, high current injectors of high q/A ions, electron cloud effects in the linacs, and chromatic focusing errors due to coherent velocity ramps for compression of neutralized bunches.

Recently, studies have considered injection, transport, and focusing of ions with q/A > 0.1 [34], and also with use of NDC with fast time-dependent kickers to compensate focusing errors due to coherent velocity ramps as large as $10 \%$ and with $>200 \mathrm{mr}$ focusing angles. Results are encouraging, but these are still works in progress. We also anticipate that if we can make beam focal spots below $1 \mathrm{~mm}$, then we may be able to access heavy ion fusion targets having requisite gains of 40 with total driver energies as low as $1 \mathrm{MJ}$ [35]. Assuming injector and final focusing studies will find conceptual solutions for injection and focusing high $\mathrm{q} / \mathrm{A}$ ions for $1 \mathrm{MJ}$ drivers, and assuming e-cloud effects can be controlled, we have meanwhile used modified versions of the IBEAM systems code [36] to make additional assessments of potential reductions in linac mass (here mass is a surrogate for cost) for MQ and MS driver cases. Recent development of high-current ECR sources of high charge state Argon ions [31] should enable injectors for $\mathrm{Ar}^{+8}$. Figure 8 shows cross sections of $1 \mathrm{MJ}$ heavy ion driver examples, one based on a scaled-down MQ driver for $\mathrm{Bi}^{+1}$ ions otherwise similar to the Robust Point Design (RPD) [37], the other a cross section for an example MS driver using $\mathrm{Ar}^{+8}$. The MQ example could use RPD-style 
injectors and focusing, while the MS driver example shown in Fig. 8 takes advantage of NDC together with time-dependent compensation of coherent velocity ramps to overlap 5 sequential bunches during drift compression to the target. Other parameters from the IBEAM systems analysis for the two examples shown in Fig. 8 are given in Table I under the columns labeled "Low q/A MQ" and High q/A MS", along with another case "High q/A MQ" that optimizes an MQ driver with $\mathrm{Ar}^{+8}$ with three sequential pulses in a manner similar to the high q/A MS driver case with 5 pulses. For reference, the original RPD driver design for $7.6 \mathrm{MJ}$ targets [37] had a total induction magnetic material (cores) mass of 35,600 tons. The $1 \mathrm{MJ}$ low q/A MQ driver case in Table I shows a weak scaling of MQ driver cost with energy with low q/A ions, namely, the 1 $\mathrm{MJ} \mathrm{Bi}{ }^{+1} \mathrm{MQ}$ driver has $2 / 3$ of the total core mass of the $7.6 \mathrm{MJ}$ RPD. In contrast, by using NDC with multiple pulses of high $\mathrm{q} / \mathrm{A}\left(\mathrm{Ar}^{+8}\right)$ ions, the linac lengths and core masses for both high $\mathrm{q} / \mathrm{A}$ $\mathrm{MQ}$ and MS driver cases are reduced about an order of magnitude from the low q/A MQ case. One particular challenge in the high q/A MQ example is the need to build very small 4T quadrupole magnets of length $9 \mathrm{~cm}$ and radius $2.6 \mathrm{~cm}$ with $7 \mathrm{~mm}$ clearance between the beam and pipe radii, to limit phase advance per half-lattice period to less than 80 degrees for $\mathrm{Ar}^{+8}$ ions.

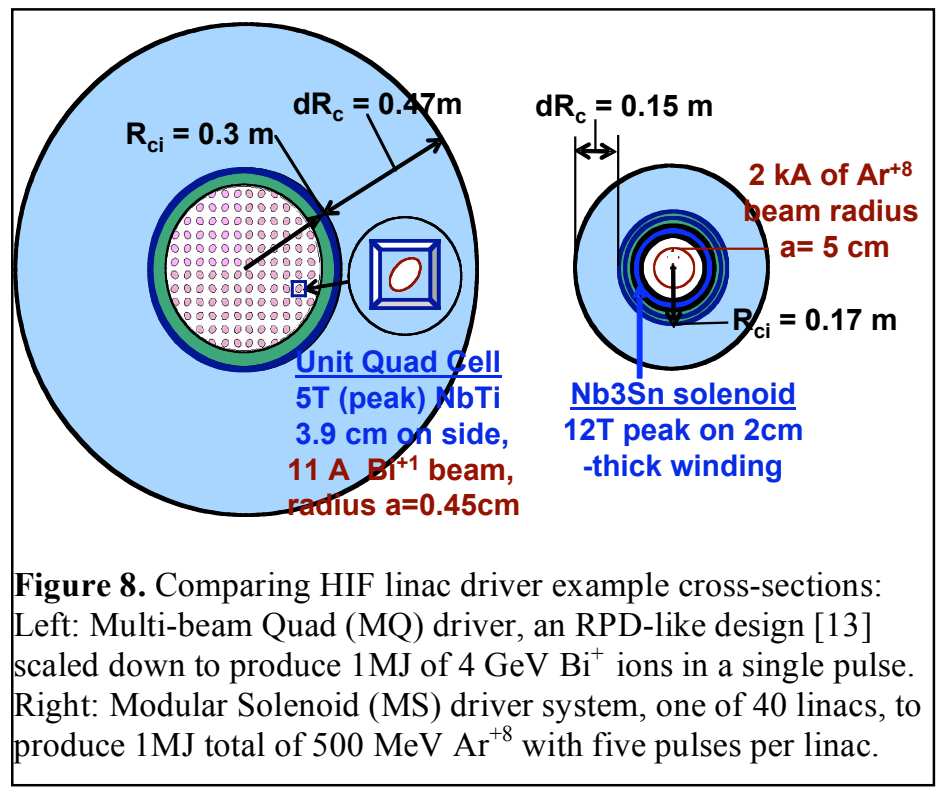

\begin{tabular}{|c|c|c|c|}
\hline Driver type & $\begin{array}{l}\text { Low q/A } \\
\text { MQ Bi }\end{array}$ & $\begin{array}{l}\text { Hi q/A } \\
\text { MQ Ar }{ }^{+8}\end{array}$ & $\begin{array}{l}\text { Hi q/A } \\
\text { MS Ar }\end{array}$ \\
\hline $\mathbf{E}_{\text {total }}(\mathbf{M J})$ & 1 & 1 & 1 \\
\hline \# Pulses & 1 & 3 & 5 \\
\hline \# Linacs & 1 & 1 & 40 \\
\hline \# Bunches & $120 \times 1$ & $150 \times 3$ & $40 \times 5$ \\
\hline Range $\left(\mathrm{g} / \mathrm{cm}^{2}\right)$ & 0.03 & 0.03 & 0.03 \\
\hline $\mathrm{Ti}_{\max }(\mathrm{MeV})$ & 4000 & 600 & 600 \\
\hline $\mathbf{T i}_{\min }(\mathrm{MeV})$ & 3300 & 500 & 500 \\
\hline Voltage (MV) & 4000 & 75 & 75 \\
\hline Length (m) & 2900 & 300* & $75 \times 40$ \\
\hline $\mathbf{I b}_{\text {injection }}(\mathrm{A})$ & 0.075 & 5.2 & 12 \\
\hline$I_{\text {final }}(\mathrm{A})$ & 11 & 176 & 2000 \\
\hline Cores (tons) & 21,400 & 1,930 & 2,400 \\
\hline Efficiency** & 0.21 & 0.55 & 0.28 \\
\hline
\end{tabular}

*includes $160 \mathrm{~m}$ ESQ section to $100 \mathrm{MeV}$

**based on core losses only.

$\mathrm{MQ}=$ Multiple beam magnetic quad linac

$\mathrm{MS}=$ Modular solenoid linac system

There are other critical needs to address. All driver cases optimized with the IBEAM systems code neglect e-cloud effects, so effective means must be found to virtually eliminate e-cloud effects in the acceleration regions of all cases. A key motivation for the e-cloud studies described in Section V comparing both solenoidal and quadrupole magnetic geometries is to evaluate the efficacy of methods to mitigate e-cloud effects in those geometries, and to be able to model small residual e-cloud effects on the beam brightness. This knowledge is essential to permit future integrated studies of both MQ and MS HIF driver approaches including various mitigation effects such as axial electron kicks in induction gaps. All induction driver cases require longitudinal bunch compression by factors of 5 to $10 \mathrm{X}$ during initial acceleration between injection and the main linac. Both the high q/A MQ and MS driver cases need multiple pulses to achieve shorter bunch durations, so as to get reasonable induction gradients together with core masses low enough for efficiencies $>25 \%$, which requires fast, efficient, and low-cost solid state 
switching. The output bunch train lengths of $50 \mathrm{~m}$ and $40 \mathrm{~m}$ for the 3-pulse MQ and 5-pulse MS driver cases require 500 to 400 meter-long NDC sections, respectively, assuming 10\% velocity ramps and chromatic error compensation between the head and tail bunches to allow the bunches to converge at the target. The detailed convergence timing should be controlled to provide the required target pulse shaping (an advantage over one-pulse linacs). An important development path advantage of the MS approach over the MQ approach is that a driver prototype can be validated with one linac module at full ion energy with $<3 \%$ of the high q/A MQ linac mass.

\section{Conclusions}

The present and planned research should provide the physics knowledge base needed to optimize the design of future heavy ion accelerators for both high energy density physics and heavy ion fusion energy drivers, including both multiple-beam quadrupole-focused linac and modular solenoid-focused linac development path options towards inertial fusion energy.

Acknowledgements: This research was performed under the auspices of the U.S. Department of Energy by the University of California, Lawrence Berkeley and Lawrence Livermore National Laboratories under Contract Numbers DE-AC02-05CH11231 and W-7405-Eng-48, and by the Princeton Plasma Physics Laboratory under Contract Number DE-AC02-76CH03073.

\section{References}

[1] P. K. Roy, S. S. Yu, S. Eylon, E. Henestroza, A. Anders, E. P. Gilson, F. M. Bieniosek, W. G. Greenway, B. G. Logan, W. L. Waldron, D. B. Shuman, D. L. Vanecek, D. R. Welch, D. V. Rose, C. Thoma, R. C. Davidson, P. C. Efthimion, I. Kaganovich, A. B. Sefkow, and W. M. Sharp, Nucl. Instr. Meth. Phys. Res. A544 (2005) 225.

[2] C. Thoma, D.R. Welch, S.S. Yu, E. Henestroza, P.K.Roy, S. Eylon, E.P. Gilson, Phys. Plasmas 12 (2005) 043102.

[3] L. R. Grisham, Phys. Plasmas 11 (2004) 5727.

[4] Roy, P.K.; Yu, S.S.; Henestroza, E.; Anders, A.; Bieniosek, F.M.; Coleman, J.; Eylon, S.; Greenway, W. G.; Leitner, M.; Logan, B.G.; Waldron, W.L.; Welch, D.R.; Thoma, C.; Sefkow, A.B.; Gilson, E.P.; Efthimion, P.C.; Davidson, Phys. Rev. Lett. 95 (2005) 234801.

[5] A. B. Sefkow, R. C. Davidson, P. C. Efthimion, E. P. Gilson, S. S. Yu, P. K. Roy, F. M. Bieniosek, J. E. Coleman, S. Eylon, W. G. Greenway, E. Henestroza, J. W. Kwan, D. L. Vanecek, W. L. Waldron and D. R. Welch, Phys. Rev. ST Accel. Beams 9 (2006) 052801.

[6] See C. Thoma, W.L. Waldron, D.R. Welch, "Neutralized Drift Compression Experiments (NDCX) with a High Intensity Ion Beam", Nucl. Instr. and Meth. Phys. Res., these proceedings.

[7] See P.K. Roy, S.S. Yu, E. Henestroza, A. Anders, D. Baca, F.M. Bieniosek, J. Coleman, R.C. Davidson, P.C. Efthimion, S. Eylon, E.P. Gilson, W.G. Greenway, I. Kaganovich, M. Leitner, B.G. Logan, A.B. Sefkow, P. Seidl, Nucl. Instr. and Meth. Phys. Res., these proceedings.

[8] See P. C. Efthimion, E. P. Gilson, L. Grisham, R. C. Davidson, S. S. Yu, W. Waldron and B. G. Logan, " Ferroelectric Plasma Source for Heavy Ion Beam Charge Neutralization", Nucl. Instr. and Meth. Phys. Res., these proceedings.

[9] See I. D. Kaganovich, E. A. Startsev, A. B. Sefkow, R. C. Davidson and D. R. Welch, "Effects of Finite Pulse Length, Electron Temperature, Solenoidal Magnetic Field, and Gas Ionization on Ion Beam Pulse Neutralization by Background Plasma", Nucl. Instr. and Meth. Phys. Res., these proceedings.

[10] See J.J. Barnard, A. Friedman, I. Kaganovich, B.G. Logan, M.M. Marinak, R.M. More, G.E. Penn, A.B. Sefkow, P. Santhanam, D.R. Welch, J.S. Wurtele, "Theory and simulation of warm dense matter targets", Nucl. Instr. and Meth., these proceedings.

[11] See F.M. Bieniosek, J. Barnard, M.A. Leitner, A.W. Molvik, R. More, P.K. Roy, "Diagnostics for near term WDM experiments", Nucl. Instr. and Meth. Phys. Res., these proceedings.

[12] See A. Sefkow, R.C. Davidson, I.D. Kaganovich, E.P. Gilson, P.K. Roy, S.S. Yu, P.A. Seidl, D.R. Welch D.V. Rose, J.J. Barnard, "Optimized Simultaneous Transverse and Longitudinal Focusing of Intense Ion Beam Pulses for Warm Dense Matter Applications”, Nucl. Instr. and Meth. Phys. Res., these proceedings. 
[13] See L. R. Grisham, J. W. Kwan, and G. Westenskow, "Halogens for Negative Ion Beams and Ion - Ion Plasmas", Nucl. Instr. and Meth. Phys. Res., these proceedings.

[14] R.J. Briggs, et al., "Helical Pulse Line Structure for Ion Acceleration", Proceedings of the 2005 Particle Accelerator Conference (IEEE, Piscataway, NJ 2005); http://accelconf.web.cern.ch/accelconf/.

[15] See J.E. Coleman , P.K. Roy, D.P. Grote, F.M. Bieniosek, W.L. Waldron, E. Henestroza, R.J. Briggs, P.A. Seidl, S.S. Yu, "Low Voltage Beam Experiments on the Pulse Line Ion Accelerator", Nucl. Instr. and Meth. Phys. Res., these proceedings.

[16] A.W. Molvik, et al., Nucl. Instrum. Meth. Phys. Res. A544, 194 (2005). See also A.W. Molvik, M. Kireeff Covo, R.H. Cohen, A. Friedman; F.M. Bieniosek, P.A. Seidl, J-L. Vay, "Quantitative electron and gas cloud experiments", Nucl. Instr. and Meth. Phys. Res., these proceedings.

[17] R. H. Cohen, et al., "Simulating Electron Clouds in Heavy Ion Beams," Phys. Plasmas 12 (2005) 056708. See also R.H. Cohen, A. Friedman, D.P. Grote (LLNL), J.-L. Vay, "Large-time-step mover for particle simulations of arbitrarily magnetized species", Nucl. Instr. and Meth. Phys. Res., these proceedings.

[18] M. Kireeff Covo, et al., "Absolute measurement of electron cloud density in a positively-charged particle beam," accepted for publication in Phys. Rev. Lett.

[19] M. Kireeff Covo et al., "Beam energy scaling of ion-induce electron yield from K+ impact on stainless steel," Phys. Rev. ST-AB 9, 063201 (2006).

[20] See J.-L. Vay, M.A. Furman, P.A. Seidl (LBNL), R.H. Cohen, A. Friedman, D.P. Grote, M. Kireeff Covo, S.M. Lund, A.W. Molvik, P.H. Stoltz, S. Veitzer, J.P. Verboncoeur, "Self-consistent simulations of heavy-ion beams interacting with electron-clouds", Nucl. Instr. and Meth. Phys. Res., these proceedings.

[21] See A. Friedman "Overview of theory and simulations in the Heavy Ion Fusion - Virtual National Laboratory" Nucl. Instr. and Meth. Phys. Res., these proceedings.

[22] R. C. Davidson, I. Kaganovich, H. Qin, E. A. Startsev, D. R. Welch, D. V. Rose and H. S. Uhm, Phys. Rev. ST Accel. Beams 7, 114801 (2004).

[23] See H. Qin, R. C. Davidson and E.A. Startsev, "Nonlinear Delta-f Particle Simulations of Collective Effects in High-Intensity Bunched Beams", Nucl. Instr. and Meth. Phys. Res., these proceedings.

[24] H. Qin, R. C. Davidson and E.A. Startsev, Phys. Rev. ST Accel. Beams 6, (2003) 014401

[25] E.A. Startsev, R.C. Davidson and H. Qin, Phys. Rev. ST Accel. Beams 8, (2005) 124201.

[26] See R. C. Davidson, M. Dorf, I.D. Kaganovich, Hong Qin, A.B. Sefkow, E.A. Startsev, D.R. Welch, D.D.

Rose, SM. Lund, "Collective Interaction Processes in Intense Heavy Ion Beam-Plasma Systems" Nucl. Instr. and Meth. Phys. Res., these proceedings.

[27] See E.A. Startsev, R.C. Davidson (PPPL) "Dynamic Stabilization of Two-Stream Instability During Longitudinal Compression of Intense Charged Particle Beam Propagation Through Background Plasma" Nucl. Instr. and Meth. Phys. Res., these proceedings.

[28] J-L. Vay, M. A. Furman, R. H. Cohen, A. Friedman, D.P. Grote, A. W. Molvik, P. Stoltz, S. Veitzer, J. Verboncoeur, "Filling in the Roadmap for Self-Consistent Electron Cloud and Gas Modeling", Proceedings of the 2005 Particle Accelerator Conference (IEEE, Piscataway, NJ 2005); http://accelconf.web.cern.ch/accelconf/.

[29] See G.A. Westenskow, D.P. Grote, (LLNL), J.W. Kwan, F. Bieniosek, "High-Brightness Heavy-Ion Injector Experiments", Nucl. Instr. and Meth. Phys. Res., these proceedings.

[30] See D.P. Grote, "Design and Modeling of the Multi-beamlet Injector", Nucl. Instr. and Meth. Phys. Res., these proceedings.

[31] S. V. Golubev, S. V. Razin, and V. G. Zorin, Rev. Sci Inst. 69 (1998) 634.

[32] W.R. Meier, B.G. Logan, Nucl. Instr. and Meth. Phys. Res., A544 (2005) 310.

[33] B.A. Prichard, Jr., J. Barraza, M. Kang, K. Nielson, F. Bieniosek, K. Chow, W. Fawley, E. Henestroza, L. Reginato, W. Waldron, R. Briggs, T. Hughes, T. Genoni, “ Technological improvements in the DARHT-II accelerator cells", Proceedings of the 2005 Particle Accelerator Conference (IEEE, Piscataway, NJ 2005), ); http://accelconf.web.cern.ch/accelconf/.

[34] E. Henestroza, J.J. Barnard, J.W. Kwan, S.S. Yu, "High Brightness Injector for Warm Dense Matter Studies" Nucl. Instr. and Meth. Phys. Res., these proceedings.

[35] D.A. Callahan-Miller, M. Tabak, Phys. Plasmas 7 (2000) 2083.

[36] W. Meier, R. Bangerter, J. Barnard, Nucl. Inst. and Meth. in Phys. Res. A464 (2001) 433.

[37] S.S. Yu, W.R. Meier, R.P. Abbott, J.J. Barnard, T. Brown, D.A. Callahan, P. Heitzenroeder, J.F.

Latkowski, B.G. Logan, S.J. Pemberton, P.F. Peterson, D.V. Rose, G-L. Sabbi, W.M. Sharp, D.R. Welch, Fusion Sci. Technol. 44 (2003) 266. 